\title{
EQUIPMENT REPLACEMENT UNDER TECHNOLOGICAL ADVANCES
}

\author{
Yasuo Kusaka \\ Tokyo Metropolitan College of Commerce
}

(Received September 2, 1985: Revised December 12, 1985)

\begin{abstract}
Suppose a problem of determining whether the replacement of old equipment is economical or not when new equipment with technological advances is expected to appear at each period of the equipment planning interval. Since equipment always keeps in danger of obsolescence under technological advances, the decision maker needs grasp the state of obsolescence constantly to reflect it adaptively in the present and future decisions. Especially the decision to replace now or not becomes urgent in most cases and he is much concerned with the present decision. At this time he must also consider the fact that the present decision depends on the subsequent future decisions. This paper derives a simple criterion by which it becomes easily possible in some circumstances to decide whether immediate replacement is economical or not without determining the subsequent sequence of replacement times for the planning interval. Some informations on next replacement time are presented by parametric analysis of the criterion and the upper bound number of replacement times is given for the interval. These will become a guideline for the decision maker to plan future equipment replacement. The proposed method is applied to a practical case and some characteristics are examined by sensitivity analysis. It is clarified that the method is relatively insensitive to changes of parameters at the present decision.
\end{abstract}

\section{Introduction}

Milling, drilling and tapping machines have been used to produce parts in an optical instrument manufacturing firm. These machines were introduced 5 years ago. Work methods by these need the setting and resetting of the parts at every process and there have been defects such as

(1) inferior precisions,

(2) higher tooling cost,

(3) more man-hours spent by handling, measurement and setting, and

(4) much floor space needed.

To improve the situation, the decision maker of the firm plans to exchange 
all the machines for the machining center after half a year. In the plan it is estimated possible to reduce the number of operators from 6 to 2, and defective products discarded by inferior precisions resulting in the decrease of total operating cost. The planned interval of replacement is 8 years from the introduction of new machine. With time, the operating cost of old machine increases, the initial operating cost of new machine decreases under technological advances, the acquisition cost of new machine increases and the disposal value of old machine decreases. It is forecasted that their changes rise respectively at constant rates per period for the interval. The decision. maker intends to discuss whether the replacement is economical or not considering the subsequent replacement times for the interval.

In the equipment replacement described above, it is important to notice that "there exists an infinite chain of replacement, that is, the present decision will be affected by the subsequent set of decisions". Since the forecast of technological advances is impossible to an infinite time horizon, a rational determination of replacement sequence is also difficult. There is such an essential difficulty in equipment replacement and how to tackle with it has been an important aspect in conventional research.

Preinreich [7] discussed an economical replacement problem with infinite time horizon under constant technology (equal life mode1). This treated with an infinite chain of replacement assuming technological advances did not occur. Terborgh [10] studied a replacement problem with technological advances, called MAPI system, assuming an adverse minimum of future challenging machines was equal to one of the present machine. This system involves some problems that the above equality is assumed and a change of equipment acquisition cost is neglected [8]. Thereafter various replacement models had been studied under technological advances. Bellman [1] formulated a replacement problem with infinite time horizon by Dynamic Programming (DP). Dreyfus [2] treated a replacement problem with plural replacement alternatives at each decision time of a finite time horizon and gave numerical examples. Elton \& Gruber [3] proved the optimality of equal life policy under the linearity assumption in MAPI. Stapleton et al. [9] modelled some non-linear types of technological advances by DP and clarified the difference between the non-1inearity assumption and the linearity of MAPI by numerical experiments. Nakamura [6] determined a sequence of replacement times by Lagrangean multiplier method for a problem in which the impact of technological advances appears in both equipment acquisition costs and annual profits, and clarified some problems in MAPI. Most of these studies stressed on model building and/or numerical solution methods. In recent years, Lin et a1. treated a problem with infinite time 
horizon, in which technical improvement appears in both equipment acquisition costs and annual operating expenses. After the basic research [4] of comparing optimal replacement interval for two cases where both the technology always keeps improving and sometimes in future it stops, they [5] proposed an approximate solution method through "two equal life models" derived from the above problem.

In such equipment replacement under technological advances as described above, the following aspects should be considered:

(1) It will be realistic that we treat the problem with infinite chain of replacement as a problem with finite planning interval feasible to forecast, and adaptively re-estimate it corresponding to changes of circumstances.

(2) Equipment always keeps in danger of obsolescence under technological advances and it is replaced only after the obsolescence proceeds to a certain degree. Therefore the decision to replace now or not becomes urgent in most cases. Here, the problem of utmost importance is not future decisions but immediate decision, and for the reason the decision maker is concerned with the present decision. At this time he must also consider the fact that the present decision will depend on the subsequent future decisions.

(3) Noticing the adaptive feature of replacement problem as described above, we need constantly grasp the state of obsolescence under technological advances by a simple method to reflect the result in future plans properly.

This paper discusses a replacement problem with finite time horizon for such equipments as NC machine tool, machining center, flexible manufacturing system etc., in which operating cost reduction and equipment acquisition cost change are expected through technological advances in both high performance and savings of manpower and other resources, from the following aspects:

(1) We derive a simple criterion by which there are some circumstances for it possible to decide the present economical choice of "keep" or "replace" without determining the subsequent sequence of all replacement times.

(2) We show that some informations on next replacement time can be obtained by parametric analysis of the criterion and give the upper bound number of replacement times for the planning interval. These will become a guideline for the decision maker to plan future replacement.

(3) We apply the proposed method to a practical case and examine some characteristics by sensitivity analysis.

The decision maker can easily monitor states of obsolescence corresponding to changes of circumstances since the introduced criterion is given in analytical and closed form. The proposed method will be more convenient and informative compared with that of determining the sequence of all replacement times 
only by numerical analysis.

\section{Description of Model}

\subsection{Replacement decision making at the present time}

The equipment introduced at the $k$-th period is operating at the present period $t$. Hereinafter we briefly write "time $k^{\prime \prime}$ instead of "the $k$-th period" and "time $t$ " instead of "the $t$-th period". A new equipment is available for replacement and a tendency of its technological advances is known for a planning period $[t, T]$. We should like to decide whether the present replacement is economical or not, as to minimize the present value of total cost considering the subsequent sequence of replacement for the planning period. We use the following notations, where "time" is represented as the beginning of the time so long as any special reference is not made. $I(u)$ : acquisition cost of new equipment at time $u$ $V(u, v)$ : disposal value at the end of time $v$ (at the beginning of time $v+1$ ) for the equipment introduced at time $u$ $h(u, v)$ : operating cost at time $v$ for the equipment introduced at time $u$

The depreciation cost is excluded.

$A=\{K, R\}$ : a set of policies,

where $K$ and $R$ represent "keep" and "replace" actions respectively. $a_{t}:$ decision at time $t$

$P_{k}{ }^{t}(t, s-1):$ present value of cost at time $t$,

where we keep the old equipment introduced at time $k\left(a_{t}=K\right)$ or replace it by new one $\left(a_{t}=R\right)$ at time $t$, operate the equipment selected at time $t$ until time $s^{-1}$ and replace it by new one at time $s$. $P_{u}(v)$ : present value of optimal cost at time $v$, where we start at time $v$ by the equipment introduced at time $u$ and follow the optimal policy after that time. Especially $u=v$ means that we start at time $v$ by new equipment.

$\alpha$ : discount rate per period in discrete compounding interest factor, where $0<\alpha<1$.

\subsection{Assumptions under technological advances}

Suppose a case where a trend of changes in technological advances, product price and volume of product can be forecasted for the planning interval. In economic quantities, there are many variables which change at constant rates according to the law of diminishing returns or the law of increasing 
returns, and there will be cases where decision maker can estimate their rates from the past experiences and the rough forecast of future technological advances as in the preceeding example.

Therefore we assume that $I(u), V(u, v)$ and $h(u, v)$ change at constant rates with respect to $u$ and $V$ as follows:

(1) Initial operating cost of new equipment which appears at time $v$ changes with time at a constant rate $\tau$ through technological advances:

$$
h(v, v)=h(u, u) \tau^{v-u} \quad u<v
$$

(2) Operating cost of new equipment is lower than that of old equipment:

$$
h(u, v)-h(v, v)>0 \quad u<v
$$

(3) Operating cost of equipment introduced at time $u$ changes with time at a constant rate $\rho$ :

$$
h(u, v)=h(u, u) \rho^{v-u} \quad u<v
$$

(4) Acquisition cost of new equipment changes with time at a constant rate $\delta$ under technological advances:

$$
I(v)=I(u) \delta^{v-u} \quad u<v
$$

(5) Disposal value of equipment decreases at a constant rate $\phi$ :

$$
V(u, v)=I(u) \phi^{v-u} \quad u<v, 0<\phi<1
$$

These are illustrated in Fig. 1.
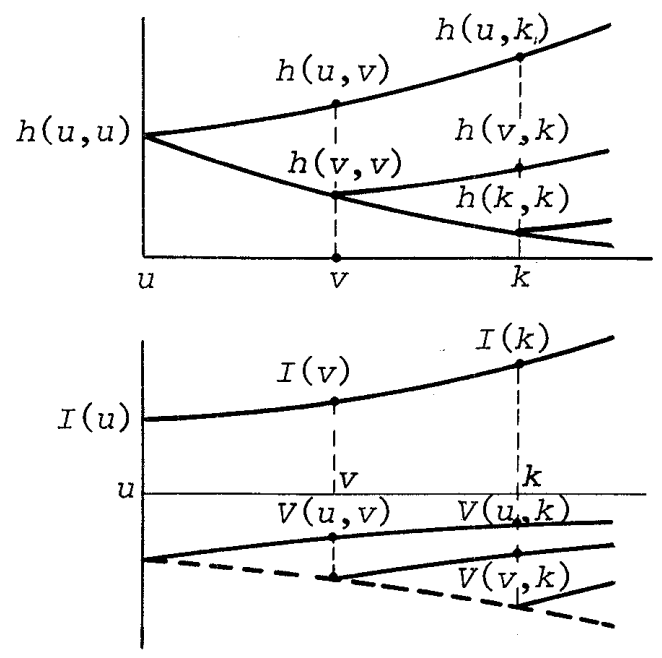

Fig. 1 Patterns of $h(u, v), V(u, v)$ and $I(u)$

\subsection{Formulation}

Suppose that we are going to decide to "keep" the old equipment introduced at time $k\left(a_{t}=K\right)$ or "replace" it by new equipment $\left(a_{t}=R\right)$ at time $t$, to operate the equipment selected at time $t$ until time $s-1$, to replace it by new equipment at time $s$ and to follow the optimal policy after this. The 
minimal total cost for $[t, T]$ under the optimal policy is given as follows:

$$
P_{k}(t)=\min _{s \in\{t+1, t+2, \ldots, T+1\}}\left[\min _{a_{t} \in A}\left\{P_{k}^{a}{ }^{t}(t, s-1)+P_{s}(s) \alpha^{s-t}\right\}\right]
$$

$$
=\min _{s \in\{t+1, t+2, \ldots, T+1\}}\left[\min _{a_{t} \in A} P^{{ }^{a}}{ }^{t}(t, s-1)+P_{s}(s) a^{s-t}\right]
$$

\section{Present Decision Making by Comparison between 01d and New Equipments}

\subsection{Choice between "keep" and "replace" actions}

Equation (2.1) generally shows that the present decision depends on the subsequent sequence of decisions. However, if the first term at the right hand side in (2.1) attains the minimum value by taking the same action $a_{t}$ for any $s$, then the present decision becomes independent from the sequence and thus we can choose the present decision without making it. Since such conditions have not been clarified quantitatively, we shall give the conditions by comparison between old and new equipments.

Suppose the following two cases; (1) the new equipment introduced at the present time $t$ operates until time $s^{-1}$ and it is replaced at time $s$, and

(2) the old equipment introduced at the past time $k$ keeps operating until time $s^{-1}$ and it is replaced at time $s$. These are illustrated in Fig. 2.

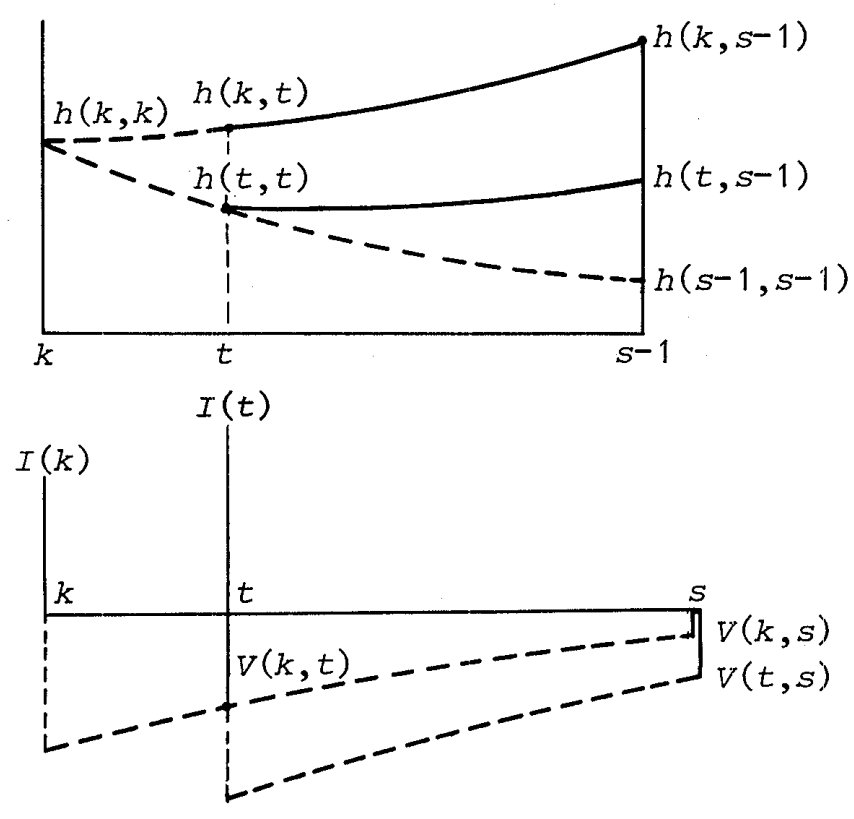

Fig. 2 Comparison between $01 d$ and New Equipments 
The difference of present value of total cost between the former and the latter becomes

$$
-\sum_{r=t}^{s-1}\{h(k, r)-h(t, r)\} \alpha^{r-t}+\{I(t)-V(k, t)\}\left\{1-(\phi \alpha)^{s-t}\right\}
$$

$$
=-\{h(k, t)-h(t, t)\} \sum_{r=t}^{s-1}(\rho \alpha)^{r-t}+I(k)\left(\delta^{t-k}-\phi^{t-k}\right)\left\{1-(\phi \alpha)^{s-t}\right\},
$$

where the assumptions (3)-(5) are used in the transformation from the left hand side to the right.

$\underline{\delta>\phi}$

$\delta>\phi$ means that the decreasing rate of new equipment acquisition cost does not exceed one of old equipment disposal value whenever the acquisition cost decreases with time and the case is considered to be natural. Therefore we first suppose the case of $\delta>\phi$. Letting (3.1) be less than or greater than zero, we have the following relations:

$$
\begin{aligned}
\frac{h(k, t)-h(t, t)}{I(t)-V(k, t)}=\frac{h(k, t)-h(t, t)}{I(k)\left(\delta^{t-k}-\phi^{t-k}\right)} & >\frac{1-(\phi \alpha)^{s-t}}{\sum_{r=t}^{s-1}(\rho \alpha)^{r-t}} \\
\text { for any } s \in\{t+1, t+2, \ldots, T+1\} & \Rightarrow R \\
& \Rightarrow K
\end{aligned}
$$

The quantity $h(k, t)-h(t, t)$ denotes the cost saving per period by immediate "replace" action in comparison with "keep" action, or the operating inferiority per period by the "keep" action compared with the "replace". The quantity $\{h(k, t)-h(t, t)\}_{r=t}^{s-1}(\rho \alpha)^{r-t}$ is interpreted as the total cost saving by "replace" action or the total operating inferiority supposing that $h(k, t)-h(t, t)$ per period occurs for the equivalent length of $\sum_{r=t}^{s-1}(\rho \alpha)^{r-t}$ periods. On the other hand, the quantity $I(t)-V(k, t)$ denotes the additional investment cost by "replace" action. The quantity $\{I(t)-V(k, t)\}\left\{1-(\phi \alpha)^{s-t}\right\}$ is interpreted as the equivalent total investment cost by the replacement in the case supposing that $I(t)-V(k, t)$ per period occurs for the equivalent length of $\left\{1-(\phi \alpha)^{s-t}\right\}$ periods. Therefore (3.2) shows that "replace" action should be chosen if the total cost saving becomes greater than the total investment cost and otherwise "keep" action should be selected. (3.2) is transformed into 


$$
\begin{aligned}
h(k, t)-h(t, t) & >\frac{1-(\phi \alpha)^{s-t}}{\sum^{s-1}(\rho \alpha)^{r-t}}(I(t)-V(k, t)) \text { for any } s \in\{t+1, t+2, \ldots, T+1\} \\
& \Rightarrow R \\
& \Rightarrow K .
\end{aligned}
$$

The quantity $\left\{1-(\phi \alpha)^{s-t}\right\} /\left\{\sum_{r=t}^{s-1}(\rho \alpha)^{r-t}\right\}$ can be equivalently interpreted as capital recovery factor which converts the additional investment cost at time $t$, namely, $I(t)-V(k, t)$, into the periodical investment cost.

$\delta<\phi$

Since (3.1) becomes negative by the assumption (2) if $\delta<\phi$, a replacement action is always chosen at the present time $t$. Since $\delta$ and $\phi$ are the parameters which represent change rates of new equipment acquisition cost and disposal value of old equipment respectively, it is natural to consider that $\delta>\phi$ holds as before. Therefore we treat only the case of $\delta>\phi$ after this.

From (3.2), we have the following relations not depending on $s$ :

$$
\begin{aligned}
& \begin{aligned}
& >E_{2}^{*}(t) \Rightarrow R \\
\eta_{k}(t) & <E_{1}^{*}(t) \Rightarrow K
\end{aligned} \\
& \text { where } \eta_{k}(t) \equiv \frac{h(k, t)-h(t, t)}{I(t)-V(k, t)}, \quad E(t, s) \equiv \frac{1-(\phi \alpha)^{s-t}}{\sum_{r=t}^{s-1}(\rho \alpha)^{r-t}} \\
& E_{1}^{*}(t) \equiv \min _{s \in\{t+1, t+2, \ldots, t+1\}} E(t, s), \quad E_{2}^{*}(t) \equiv \max _{s \in\{t+1, t+2, \ldots, t+1\}} E(t, s)
\end{aligned}
$$

$\eta_{k}(t)$ and $E(t, s)$ represent the ratio of cost saving to additional investment cost at time $t$, namely, an efficiency of additional investment at time $t$, and an equivalent capital recovery factor of additional investment at time $t$ respectively. If the condition of (3.4) is satisfied, we can simply choose the present decision without making the subsequent sequence of decisions. In case of $E_{1}^{*}(t)<\eta_{k}(t)<E_{2}^{*}(t)$, we must make the present decision by numerical analysis (for convenience, we denote the case by $a_{t}=N$ from now on). However, an important aspect lies in the fact that we can grasp quantitatively and constantly the state of obsolescence of old equipment, and obtain necessary informations for future decisions.

With respect to $E_{1}^{*}(t)$ and $E_{2}^{*}(t)$ in $(3.4)$, we can easily show the following relations hold: 
(3.5)

$$
\begin{aligned}
& E_{1}^{*}(t)= \begin{cases}E(t, T+1) & \rho>\phi \\
1-\phi \alpha & \rho=\phi \\
1-\phi \alpha & \rho<\phi\end{cases} \\
& E_{2}^{*}(t)= \begin{cases}1-\phi \alpha & \rho>\phi \\
1-\phi \alpha & \rho=\phi \\
E(t, T+1) & \rho<\phi\end{cases}
\end{aligned}
$$

Notice that the present decision is completely divided into two patterns of $a_{t}=R$ and $a_{t}=K$ in case of $\rho=\phi$.

\subsection{Informations on next decision}

If the decision maker can know the state of $a_{t+1}$ (namely, $a_{t+1}=R, K$ or $N$ ) in case of $a_{t}=R$, the time until which "keep" action continues to be taken in case of $a_{t}=K$ or the time until which "next replace" action is certainly or possibly taken in case of $a_{t}=N$, he will be able to make the replacement decision rationally. We will show the process to obtain these informations.

Denote the present time by $n$ for the parameteric case $(n=t, t+1, \ldots, T)$. If the state of present time $n$ is considered to be extended from that of past time $k$, then (3.4) is rewritten

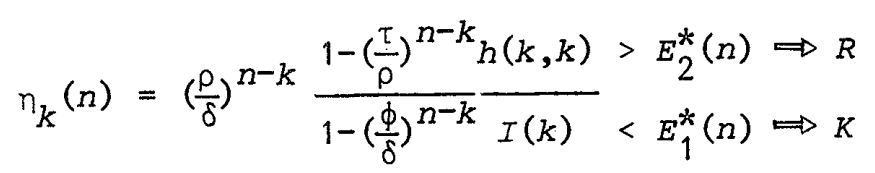

for any $n$ with $n \in\{t, t+1, \ldots, T\}$.

On the contrary if it is not considered so by some corrections of forecast, $(3.4)$ is rewritten

$$
\begin{aligned}
\eta_{k}(n)=\left(\frac{\rho}{\delta}\right)^{n-t} \frac{1-\frac{h(t, t)}{h(k, t)}\left(\frac{\tau}{\rho}\right)^{n-t}}{1-\frac{V(k, t)}{I(t)}\left(\frac{\phi}{\delta}\right)^{n-t}} \frac{h(k, t)}{I(t)}<E_{2}^{*}(n) \Longrightarrow R \\
<E_{1}^{*}(n) \Longrightarrow K
\end{aligned}
$$

for any $n$ with $n \in\{t, t+1, \ldots, T\}$.

Hereinafter we treat the case of (3.6), but notice that we can treat the case of (3.7) by a little correction of the former.

$E\left(n, T^{+1}\right)$ is increasing in $n$ in case of $\rho>\phi$, decreasing in $n$ in case of $\rho<\phi$ and equal to $1-\phi \alpha$ in case of $\rho=\phi$. There also holds $E_{1}^{*}(T)=E_{2}^{*}(T)=1-\phi \alpha$. Therefore the relation between $E_{1}^{*}(n)$ and $E_{2}^{*}(n)$ in (3.6) is classified into three patterns of (a) $\rho>\phi$, (b) $\rho<\phi$ and (c) $\rho=\phi$ (see Fig. 3). 


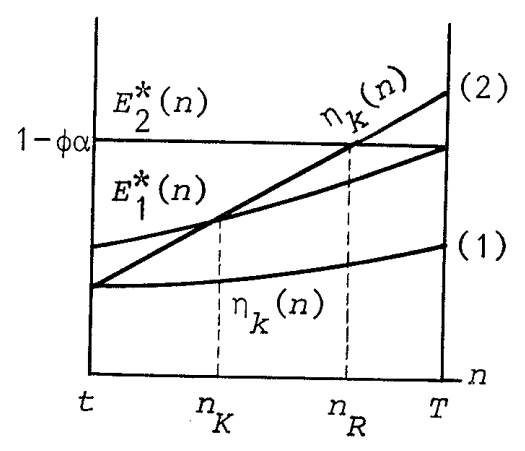

(a) $\rho>\phi$

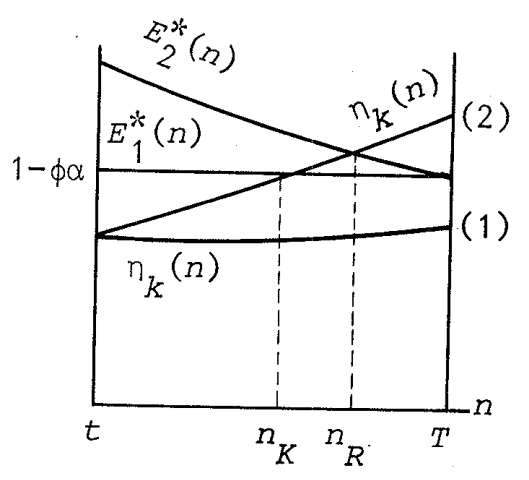

(b) $\rho<\phi$

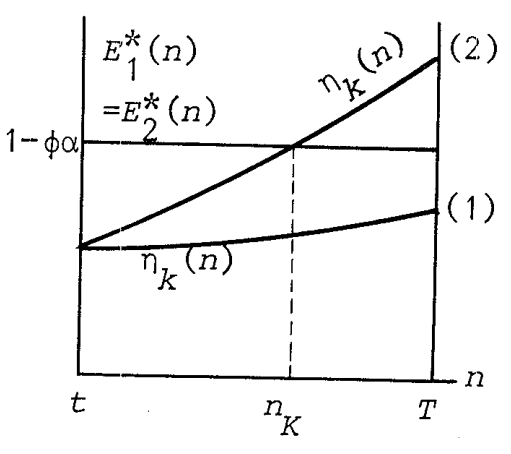

(c) $\rho=\phi$

Fig. 3 Possible Patterns of $\eta_{k}(n), E_{1}^{*}(n)$ and $E_{2}^{*}(n)$ in the Case of $a_{t}=K$

\section{Case of $a_{t}=K$}

Typical patterns of $\eta_{k}(n), E_{1}^{*}(n)$ and $E_{2}^{*}(n)$ for parametric changes of $n$ are illustrated in Fig. 3, where it is assumed that "keep" action is taken at every time $n$ since the present time $t$. Further assuming that $\eta_{k}(n)$ and $E_{1}^{*}(n)$ intersect at most one point, we can consider the following two cases of (1) and (2) for each case of (a), (b) and (c):

Case (1): $\eta_{k}(n)$ is less than $E_{1}^{*}(n)$ for every $n$ in $\left[t, T^{\prime}\right]$. In the case it is economical never to take "replace" action for $[t+1, T]$. We define $n_{K}$ as $n_{K}=T$ in the sense of denoting the largest $n$ satisfing $n_{k}(n)<E_{1}^{*}(n)$ by $n_{K}$.

Case (2): In case of $\rho \neq \phi, \eta_{k}(n)$ and $E_{1}^{*}(n)$, and $\eta_{k}(n)$ and $E_{2}^{*}(n)$ intersect once respectively. Denote the largest $n$ satisfing $n_{k}(n)<E_{1}^{*}(n)$ and the smallest $n$ satisfing $n_{k}(n)>E_{2}^{*}(n)$ by $n_{K}$ and $n_{R}$ respectively. The case indicates that we take "keep" action until time $n_{K}$ (namely, $a_{n}=K$ at every $n$ in $\left[t, n_{K}\right]$ ), enter the region impossible to decide at time $n_{K}+1$ and reach the region to replace at time $n_{R}$. This implies that next replacement surely occurs at a certain time in $\left[n_{K}+1, n_{R}\right]$. In case of $\rho=\phi, \eta_{k}(n)$ and $E_{1}^{*}(n)$ (or $E_{2}^{*}(n)$ ) intersect once. Denote the largest $n$ satisfing $\eta_{k}(n)<E_{1}^{*}(n)$ by $n_{K}$. The case means that it is economical never to replace till time $n_{K}\left(a_{n}=K\right.$ at every time $n$ in $\left.\left[t, n_{K}\right]\right)$ and is economical to replace at time $n_{K}+1$.

\section{Case of $a_{t}=N$}

Typical patterns of $\eta_{k}(n), E_{1}^{*}(n)$ and $E_{2}^{*}(n)$ for parametric changes of $n$ are illustrated in Fig. 4, where it is assumed that "keep" action is taken at every time $n$ since time $t$. Further we can consider two cases of (1) and (2) for each case of (a) and (b). Denoting the smallest $n$ satisfing $\eta_{k}(n)<E_{1}^{*}(n)$ in the case (1) and the smallest $n$ satisfing $\eta_{k}(n)>E_{2}^{*}(n)$ in the case (2) by $n_{K}^{\prime}$ and $n_{R}^{\prime}$ respectively. These cases are explained as follows: 


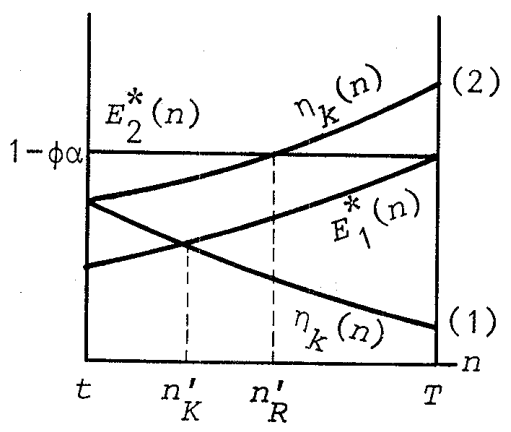

(a) $\rho>\phi$

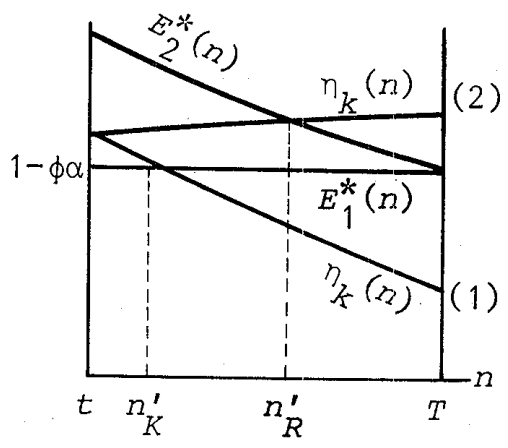

(b) $\rho<\phi$

Fig. 4 Possible Patterns of $\eta_{k}(n), E_{1}^{*}(n)$ and $E_{2}^{*}(n)$ in the Case of $a_{t}=N$

Case (1): If "keep" action is taken till time $n_{K}^{\prime}-1$, "keep" action is also selected at every time since time $n_{K}^{\prime}$. This means that "replace" action should be taken at a certain time $n$ in $\left[t, n_{K}^{\prime}-1\right]$ whenever replacement occurs at least once.

Case (2): If "keep" action is taken until time $n_{R}^{\prime-1}$, "replace" action is surely selected at time $n_{R}^{\prime}$. This implies that "replace" action should be taken at a certain time $n$ in $\left[t, n_{R}^{\prime}\right]$ whenever replacement occurs at least once.

With the information of $t_{K}^{\prime}$ or $t_{R}^{\prime}$, the decision maker will be able to limit the possible region of next replacement time.

Case of $a_{t}=R$

From (3.6) we can examine the time $t$ ' when we replace at every time $n$ in $\left[t, t^{\prime}\right] \quad\left(a_{n}=R\right.$ at every time $n$ in $\left.\left[t, t^{\prime}\right]\right)$ and reach the region either to keep $\left(a_{t^{\prime}+1}=K\right)$ or impossible to decide $\left(a_{t^{\prime}+1}=N\right)$ at time $t^{\prime}+1$. From the practical point of view, there will be many cases of $t^{\prime}=t$ since "replace" action can not be taken at the time immediately after replacement. We can treat it, as the case of $a_{t}=K$ by putting $t^{\prime+1}$ into $t$ if $a_{t^{\prime}+1}=K$ and as the case of $a_{t}=N$ by putting $t^{\prime+1}$ into $t$ if $a_{t^{\prime}+1}=N$.

From the above analysis, we obtain $n_{K}$ and/or $n_{R}$ in case of $a_{t}=K$, and, either $n_{K}^{\prime}$ or $n_{R}^{\prime}$ in case of $a_{t}=N$.

\subsection{Sufficient conditions of $\eta_{k}(n)$ for monotonous function}

It $\eta_{k}(n)$ is monotonous with respect to $n$, we can obtain necessary and sufficient conditions for existence of each case in 3.2. either exactly or approximately in the sense of assuming that $\eta_{k}(n)$ and $E_{1}^{*}(n)$ intersect at most one point. We do not intend to describe them, but rather give sufficient conditions of $\eta_{k}(n)$ for monotonous function in order to use in the subsequent analysis. 
With respect to $\delta, \phi, \tau$ and $\rho$ in (3.6), $\tau<\rho$ means that (1) if $\rho<1$, then the reduced proportion of initial operating cost by new equipment under technological advances is larger than that of operating cost by old equipment and (2) if $\rho>1$, then the change rate of initial operating cost by new equipment does not exceed the increasing rate of operating cost by old equipment. Therefore $\tau / \rho<1$ is considered to be natural together with $\phi / \delta<1$. Then the following relations hold corresponding to $\rho / \delta<1$ and $\rho / \delta>1$ :

(1) If $\frac{\phi}{\delta}<\frac{\tau}{\rho}<1<\frac{\delta}{\rho}$, then $\eta_{k}(n)$ is decreasing in $n$.

(2) If $\frac{\tau}{\rho}<\frac{\phi}{\delta}<1<\frac{\rho}{\delta}$, then $\eta_{k}(n)$ is increasing in $n$.

Dividing the condition of (1) into $\frac{\phi}{\delta} \rho<\tau<\rho$ and $\rho<\delta$, we can consider the typical case where technological advances are not so remarkable and the increasing rate of acquisition cost is large. While dividing the condition of (2) into $\tau<\frac{\phi}{\delta} \rho$ and $\phi<\delta<\rho$, we can consider the typical case where technological advances are remarkable and new equipment aquisition cost is decreasing with time.

Though we suppose the case of (3.6) at introducing (3.8), we can easily correct (3.8) by adding another condition in case of (3.7).

\section{Informations on the Frequency of Replacement}

\subsection{Role of $u^{\star}$ and $v^{*}$ in replacement decision making}

Suppose the existence of $u^{*}$ and $v^{*}$, where it is economical to replace old equipment by new one at most once for $\left(t, u^{*}\right]$ and $\left[v^{*}, T\right)$. That is, the decision maker never need replace old equipment by new one, from time $n+1$ till time $u^{*}$ if the first "replace" action is taken at a certain time $n$ in $\left(t, u^{*}\right]$, and from time $n+1$ to time $T$ if "replace" action is selected at a certain time $n$ in $\left[v^{*}, T\right)$. From $u^{*}$ and $v^{*}$, he can also determine the upper bound number of replacement times for $[t, T]$. These informations offer the decision maker a guideline on future equipment replacement.

\subsection{Determination of $u^{*}$ and $v^{*}$}

Determination of $v^{*}$

Suppose the following two cases; (1) the equipment introduced at time $v$ is replaced by new equipment at time $j(v<j<T+1)$ and it is kept operating until time $T$, and (2) the equipment introduced at time $v$ is kept operating until time $T$ (put $k, t$ and $s-1$ into $v, j$ and $T$ respectively in $F i g .2$ ). 
The difference of present value of total cost between the former and the latter is

$$
\begin{aligned}
& -\alpha^{j-v}(h(v, j)-h(j, j)) \sum_{r=j}^{T}(\rho \alpha)^{r-j}+\alpha^{j-v}(I(j)-v(v, j))\left\{1-(\phi \alpha)^{T+1-j}\right\} \\
& \quad=-\alpha^{j-v}(h(v, j)-h(j, j)) \sum_{r=j}^{T}(\rho \alpha)^{r-j}+\alpha^{j-v} I(v)\left(\delta^{j-v}-\phi^{j-v}\right)\left\{1-(\phi \alpha)^{T+1-j}\right\},
\end{aligned}
$$

where the assumptions (3)-(5) are used in the transformation from the left hand side to the right.

Noticing the case where $(4.1)$ is greater than zero, we have the following relation:

If $\delta>\phi$ and $n_{V}(j)<E\left(j, T^{+1}\right)$ for one $v \in\{t, t+1, \ldots, T-1\}$ and any $j \in\{v+1, \ldots, T\}$,

then it is economical not to replace at any intermediate time $j$ of $(v, T+1)$, where $\eta_{V}(j)$ and $E\left(j, T^{+1}\right)$ have been defined in (3.4).

\section{Definition 1}

Suppose there exists such the $v^{*}$ that the conditions of $(4.2)$ hold for any $v$ with $v \in\left\{v^{*}, v^{*}+1, \ldots, T^{-1}\right\}$ and don't hold for the $v$ with $v=v^{*}-1$, and let the set $\left\{v^{*}, v^{*}+1, \ldots, T-1\right\}$ be $x_{v}$.

Then the following relations hold:

(1) If we introduce a new equipment at any $v$ with $v \in x_{v}$, then it is economical not to replace at any intermediate time $j$ of $(v, T+1)$.

(2) The number of replacement times for $\left[V^{*}, T+1\right)$ becomes at most one from (1).

The reason why (1) holds is as follows:

Assume that $p$ times of replacement since time $v$ become most economical and let the replacement times be $v_{1}, v_{2}, \ldots, v_{p-1}$ and $v_{p}\left(v_{1}<v_{2}<\ldots<v_{p-1}<v_{p}<T+1\right)$. We notice time $v_{p-1}$. Since $v_{p-1} \in x_{v}$, it becomes economical not to replace any more since time $v_{p-1}$ from the definition of $\boldsymbol{x}_{v^{*}}$ Thus we have $v_{p-1}=v_{p}$. We can obtain $v=v_{1}=v_{2}=\ldots=v_{p}$ through repetitive applications of similar argument.

Last we refer to the determination process of $v^{*}$ from (4.2) and Definition 1. We first examine whether the second condition of (4.2) is satisfied or not for every $j$ in $[v+1, T]$ at $v=T-1$, namely, for $j=T$ in this case. If the condition is satisfied for all $j^{\prime} \mathrm{s}$, we next proceed the checking process at $v=T-2$. By repeating it, we can find such the $V^{*}$ that the second condition of (4.2) is satisfied at $v=v^{*}$ and is not satisfied at $v=v^{*}-1$. 
Determination of $u^{*}$

Suppose the following two cases; (1) we replace at any intermediate time $j$ of $(t, u)$, and (2) we never replace at any intermediate time $j$ of $(t, u)$.

It is easily shown that we have the following relation in place of (4.2) by putting $v$ and $T+1$ in section 4.2 into $t\left(a_{t}=R\right)$ or $k\left(a_{t}=K\right)$, and $u$ respectively:

If $\delta>\phi$ and, $n_{t}(j)<E(j, u) \quad\left(a_{t}=R\right)$ or $n_{k}(j)<E(j, u) \quad\left(a_{t}=K\right)$ for one $u \in\{t+2, t+3, \ldots, t+1\}$ and any $j \in\{t+1, t+2, \ldots, u-1\}$, (4.4) then it is economical not to replace at any intermediate time $j$ of $(t, u)$, where $\eta_{t}(j)$ or $\eta_{k}(j)$, and $E(j, u)$ have been defined in (3.4).

\section{Definition 2}

Suppose there exists such the $u^{*}$ that the conditions of (4.4) hold for any $u$ with $u \in\left\{t+2, t+3, \ldots, u^{*}\right\}$ and do not hold for the $u$ with $u=u^{*}+1$, and let the set $\left\{t+2, t+3, \ldots, u^{*}\right\}$ be $x_{u}$.

Then the following relations hold:

(1) If we replace old equipment at any time $u$ with $u \in \boldsymbol{x}_{u}$, then it is economical not to replace at any intermediate time $j$ of $(t, u)$.

(2) It is shown the number of replacement times for $\left(t, u^{*}\right]$ including the replacement at time $u^{*}$ becomes at most one from (1).

We can determine $u^{*}$ from (4.4) and Definition 2 in the same way as the case of $v^{*}$.

\subsection{Determination of $u^{*}$ and $v^{*}$ for a practical case}

It is natural to assume that $\phi<1$ and $\rho>1$ hold with respect to (3.5), or, Fig. 3 and Fig. 4. There will be many cases where the condition (1) of $(3,8)$ holds as before. Therefore the following conditions, which involve $\rho>\phi$ in (3.5), $\delta>\phi$ in (4.2) and (4.4), and the condition (1) of (3.8), are considered to be mild and practical:

$$
\begin{aligned}
& \rho>\phi \\
& \frac{\phi}{\delta}<\frac{\tau}{\rho}<1<\frac{\delta}{\rho}
\end{aligned}
$$

If we assume (4.6), we can easily rewrite the second conditions of (4.2) and (4.4), and thus determine $u^{*}$ and $v^{*}$ as follows. 
Determination of $\mathrm{v}^{*}$

If (4.6) holds, then the second condition of (4.2) can be rewritten

$$
\eta_{V}(v+1)=\frac{\rho-\tau}{\delta-\phi}\left(\frac{\rho}{\delta}\right)^{v-t} \frac{h(t, t)}{I(t)}<\frac{1-(\phi \alpha)^{T-V}}{\sum_{r=v+1}^{T}(\rho \alpha)^{r-(v+1)}}=E(v+1, T+1)
$$

for one $v \in\{t, t+1, \ldots, t-1\}$,

where $n_{V}(v+1)$ and $E(v+1, T+1)$ have been defined in (3.4).

Since we can easily show that, under the assumption (4.6), $\eta_{V}(v+1)$ and $E(v+1, T+1)$ become decreasing and increasing in $v$ respectively, we can determine $v^{*}$ from (4.2), Definition 1 and (4.7) as follows:

Assumes that (4.6) holds.

(1) If $n_{t}(t+1)<E(t+1, T+1)$, then $v^{*}=t$ and $x_{v}=\{t, t+1, \ldots, T-1\}$.

(2) If $\eta_{t}(t+1)>E(t+1, T+1)$ and $\eta_{T-1}(T)<E(T, T+1)$, then $v^{*}=v_{0}$ and

$$
x_{v}=\left\{v_{0}, v_{0}+1, \ldots, T-1\right\} \text {. }
$$

(3) If $\eta_{T-1}(T)>E(T, T+1)$, then there does not exist $v^{*}$ and $x_{V}=\emptyset$, where $v_{0}$ is the smallest natural number $v$ satisfing $\eta_{V}(v+1)<E(v+1, T+1)$.

Determination of $u^{*}$

Case of $a_{t}=R$

If (4.6) holds, then in the same way, the second condition of (4.4) can be rewritten

$$
\eta_{t}(t+1)=\frac{\rho-\tau}{\delta-\phi} \frac{h(t, t)}{I(t)}<\frac{1-(\phi \alpha)^{u-(t+1)}}{\sum_{r=t+1}^{u-1}(\rho \alpha)^{r-(t+1)}}=E(t+1, u)
$$

for one $u \in\{t+2, t+3, \ldots T+1\}$.

Since $E(t+1, u)$ becomes decreasing in u under the assumption (4.6), we can determine $u^{*}$ from (4.4), Definition 2 and (4.9) as follows:

Assume that (4.6) holds.

(1) If $n_{t}(t+1)<E(t+1, T+1)$, then $u^{*}=T+1$ and $x_{u}=\{t+2, t+3, \ldots, T+1\}$.

(2) If $E(t+1, T+1)<n_{t}(t+1)<E(t+1, t+2)$, then $u^{*}=u_{0}$ and

(4.10) $\quad x_{u}=\left\{t+2, t+3, \ldots, u_{0}\right\}$.

(3) If $E(t+1, t+2)<\eta_{t}(t+1)$, then there does not exist $u^{*}$ and $x_{u}=\varnothing$, where $u_{0}$ is the largest natural number $u$ satisfing $n_{t}(t+1)<E(t+1, u)$. 
Case of $a_{t}=K$

If (4.6) holds, then the second condition of (4.4) can be rewritten

$$
\eta_{k}(t+1)=\left(\frac{\rho}{\delta}\right)^{t+1-k} \frac{1-\left(\frac{\tau}{\rho}\right)^{t+1-k}}{1-\left(\frac{\phi}{\delta}\right)^{t+1-k}} \frac{h(k, k)}{I(k)}
$$

$$
<\frac{1-(\phi \alpha)^{u-(t+1)}}{\sum_{r=t+1}^{u-1}(\rho \alpha)^{r-(t+1)}}=E(t+1, u) \text { for one } u \in\{t+2, t+3, \ldots, T+1\}
$$

and $E(t+1, u)$ is decreasing in $u$. Therefore we can determine the $u^{*}$ from $(4.4)$, Definition 2 and $(4.11)$ as follows:

Assume that (4.6) holds.

(1) If $\eta_{k}(t+1)<E(t+1, T+1)$, then $u^{*}=T+1$ and $x_{u}=\{t+2, t+3, \ldots, T+1\}$.

(2) If $E(t+1, T+1)<\eta_{k}(t+1)<E(t+1, t+2)$, then $u^{*}=u_{0}$ and $x_{u}=\left\{t+2, t+3, \ldots, u_{0}\right\}$.

(4.12) (3) If $E(t+1, t+2)<n_{k}(t+1)$, then there does not exist $u^{*}$ and

$$
\begin{aligned}
& x_{u}=\varnothing, \\
& \text { where } u_{0} \text { is the largest natural number } u \text { satisfing }
\end{aligned}
$$$$
\eta_{k}(t+1)<E(t+1, u) \text {. }
$$

\subsection{Upper bound number of replacement times}

We consider the upper bound number of replacement times except the present replacement and denote it by $m_{\mathrm{o}}$.

When we define as $u^{*}=t$ if $\boldsymbol{x}_{\boldsymbol{u}}=\emptyset$ and as $v^{*}=T$ if $\boldsymbol{x}_{V}=\emptyset$, it $c$ an be shown the following relations hold from $(4.3)$ and (4.5):
(1) If $u^{*}=t$ and $v^{*} \neq t$, then $m_{0}=v^{*}-t$.
(2) If $t+2 \leqq u^{*}<v^{*}$, then $m_{0}=v^{*}-u^{*}+1$.
(3) If $t \neq v^{*} \leqq u^{*} \neq T+1$, then $m_{0}=2$.
(4) If $t=v^{*} \leqq u^{*} \neq T+1$, then $m_{0}=1$.
(5) If $u^{*}=T+1$, then $m_{0}=0$.

Therefore we have $m$, which is the upper bound number of replacement times including the present replacement, as follows:

(1) If $a_{t}=R$, then $m=m_{0}+1$.

(2) If $a_{t}=K$, then $m=m_{0}$. 


\section{Case Study}

We show some results by the application of the above analysis to the preceeding example.

A set of parameters in this cases is given in Table 1. It satisfies the condition (4.6). A planning interval of replacement ranges from the twentythird period considered as representing the present time $t$ to the fifty-forth period representing the last time $T, V(k, t)$ and $h(k, t)$ represent the disposal value and the operating cost of old equipment at time $t$ respectively, and $I(t)$ and $h(t, t)$ represent the equipment acquisition cost and initial operating cost of new equipment at the present time $t$ respectively (unit cost represents ten thousand yen). Notice that the standard values at Table 1 are assumed to remaining parameters except one in sensitivity analysis.

Table 1 Standard Values of Parameters

\begin{tabular}{|l|l|l|l|}
\hline$t: 23$ & $\tau: 0.98158$ & $\delta: 1.01706$ & $V(k, t): 780$ \\
$T: 54$ & $(0.8 / 3$ years $)$ & $(1.07 /$ year $)$ & $I(t, t): 5000$ \\
$\alpha: 0.97400$ & $\rho: 1.01227$ & $\phi: 0.93057$ & $h(k, t): 2455$ \\
$(0.9 /$ year $)$ & $(1.05 /$ year $)$ & $(0.1 /$ years $)$ & $h(t, t): 985$ \\
\hline
\end{tabular}

Table 2 shows the present decision $a_{t}$, "at most $m$ times of replacement" and the comparison of $m$ with the optimal policy by DP method. In the practical case of $I(t)=5000, a_{t}=R$ and "at most 4 times of replacement" are obtained when the optimal replacement times are 23,27 and 37. Notice that the present replacement can be determined by the criterion without making the subsequent future decisions. Especially the information on $m$ becomes effective when the number of replacement is small for the planning interval. When $I(t)$ successively increases by 500, we reach a region where we can not determine a course of action at $I(t)=16500$. For further increase in $I(t)$, we enter an region of "keep" $\left(a_{t}=K\right)$ at $I(t)=41000$.

Fjg. 5 indicates that the case (2) of (a) in Fig. 4 occurs at time $t+1$ in the practical case. We enter the region impossible to decide at time $24 \mathrm{im}-$ mediately after "replace" action at time 23 and obtain $n_{R}^{\prime}=34$. This implies that next "replace" action should be taken at a certain time in [24,34] and thus the possible region of next replacement time can be limited to the interval. 
Table 2 Present Decision and Upper Bound Number of Replacement Times

\begin{tabular}{|c|c|c|c|c|c|c|c|c|c|}
\hline \multirow[b]{2}{*}{$I(t)$} & \multirow[b]{2}{*}{$n_{k}(t)$} & \multirow[b]{2}{*}{$E_{1}^{*}(t)$} & \multirow[b]{2}{*}{$E_{2}^{*}(t)$} & \multirow[b]{2}{*}{$a_{t}$} & \multirow[b]{2}{*}{$u^{*}$} & \multirow[b]{2}{*}{$v^{*}$} & \multirow[b]{2}{*}{$m$} & \multicolumn{2}{|c|}{ Optimal Policy } \\
\hline & & & & & & & & $\begin{array}{l}\text { Replacement } \\
\text { Time }\end{array}$ & Cost \\
\hline 4500 & 0.395161 & 0.036920 & 0.093619 & $R$ & 29 & 36 & 9 & $23,29,38$ & 26641.6 \\
\hline 5000 & 0.348341 & $"$ & $n$ & $R$ & 32 & 34 & 4 & $23,27,37$ & 27483.4 \\
\hline 5500 & 0.311441 & $"$ & $"$ & k & 35 & 32 & 3 & 23,35 & 28279.6 \\
\hline 10000 & 0.159436 & $"$ & $"$ & $R$ & 55 & 23 & 1 & 23 & 34320.6 \\
\hline 15000 & 0.103376 & $"$ & $"$ & $R$ & 55 & 23 & 1 & 23 & 39105.3 \\
\hline 16500 & 0.093512 & $"$ & $"$ & $N$ & 23 & $\begin{array}{l}23\left(a_{t}=K\right) \\
55\left(a_{t}=R\right)\end{array}$ & 1 & 23 & 40540.8 \\
\hline 41000 & 0.036549 & $"$ & $"$ & K & 55 & 23 & 0 & - & 63599.6 \\
\hline
\end{tabular}

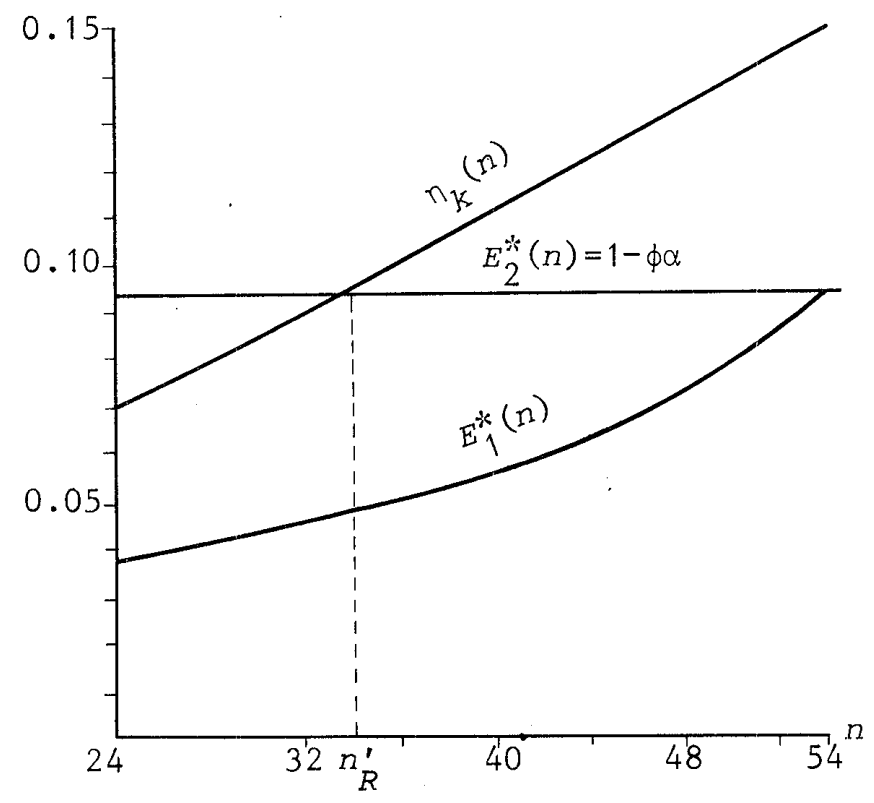

Fig. 5 Parametric Changes of $\eta_{k}(n), E_{1}^{*}(n)$ and $E_{2}^{*}(n)$

Table 3 shows how the optimal policy will change for various values of $h(k, t)$ when $\rho, \tau$ and $\delta$ respectively take the values of $0.97400 /$ period $(0.90 /$ year), $0.98726 /$ period (0.95/year), ... and $1.02411 /$ period( $1.05 /$ year), and $\phi$ takes the values of $0.82540 /$ period (0.1/3years), $0.86596 /$ period(0.1/4years), ... and $0.92106 /$ period(0.1/7years). In the cases of $h(k, t)=1500$ and 2455 , including the practical case of $h(k, t)=2455$, the present decision becomes "replace" $\left(a_{t}=R\right)$ for all cases though the sequence of optimal replacement times since 
the second replacement fairly changes when $\rho, \tau, \delta$ and $\phi$ increase. That is to say, the present decision becomes insensitive if the initial operating cost of new equipment is fairly reduced compared with the operating cost of old equipment .

In the case of $h(k, t)=1200$, where the reduction of initial operating cost of new equipment is relatively small, the first replacement time slightly changes with an increase in $\rho, \tau, \delta$ and $\phi$. However, if we seperate the case into two cases by considering whether the value of each parameter is greater than 1 or smaller than 1 , the present decision also becomes insensitive for each case.

Table 3 Effect of $\rho, \tau, \delta$ and $\phi$ on Optimal Policy

\begin{tabular}{|c|c|c|c|c|}
\hline & & \multicolumn{3}{|c|}{ Optimal Replacement Time } \\
\hline & & & $h(k, t)$ & \\
\hline \multicolumn{2}{|c|}{ per period } & 1200 & 1500 & 2455 \\
\hline \multirow{5}{*}{$\rho$} & 0.97400 & - & 23 & 23 \\
\hline & 0.98726 & - & 23 & 23 \\
\hline & 1.0 & 30 & 23 & 23 \\
\hline & 1.01227 & 30,38 & $23,27,37$ & $23,27,37$ \\
\hline & 1.02411 & $29,34,42$, & $23,24,26,29,34,42$ & $23,24,26,29,34,42$ \\
\hline \multirow{5}{*}{$\tau$} & 0.97400 & 30,38 & $23,25,29,38$ & $23,25,29,38$ \\
\hline & 0.98726 & 33 & 23,35 & 23,35 \\
\hline & 1.0 & 29 & 23 & 23 \\
\hline & 1.01227 & 23 & 23 & 23 \\
\hline & 1.02411 & 23 & 23 & 23 \\
\hline \multirow{5}{*}{$\delta$} & 0.97400 & $23-53$ & $23-53$ & $23-53$ \\
\hline & 0.98726 & $29-53$ & $23-53$ & $23-53$ \\
\hline & 1.0 & $30,36,44$ & $23,26,30,36,44$ & $23,26,30,36,44$ \\
\hline & 1.01227 & 30,39 & $23,29,39$ & $23,29,39$ \\
\hline & 1.02411 & 33 & 23,34 & 23,34 \\
\hline \multirow{5}{*}{$\phi$} & 0.82540 & 33 & 23,36 & 23,36 \\
\hline & 0.86596 & 33 & 23,35 & 23,35 \\
\hline & 0.89112 & 33 & 23,35 & 23,35 \\
\hline & 0.90852 & 33 & 23,35 & 23,35 \\
\hline & 0.92106 & 33 & 23,35 & 23,35 \\
\hline
\end{tabular}


Table 4 gives how the sequence of optimal replacement times changes for various values of $h(k, t)$ when the planning interval varies from 3 years to 10 years. Though the number of replacement times increases as the planning interval becomes long, the first replacement time does not almost change. This implies that the present decision is mainly depent on nearer future because of the effect of discount. From the fact, we will not need try to select the planning interval exactly.

Table 4 Effect of Planning Interval on Optima1 Policy

\begin{tabular}{|c|c|c|c|c|c|c|c|c|}
\hline \multirow{3}{*}{$h(k, t)$} & \multicolumn{8}{|c|}{ Optimal Replacement Time } \\
\hline & $T=34$ & $T=38$ & $T=42$ & $T=46$ & $T=50$ & $T=54$ & $T=58$ & $T=62$ \\
\hline & 3ys. & 4ys. & 5ys. & 6ys. & $7 y s$. & $8 y s$. & $9 y s$. & 10ys. \\
\hline \multirow[t]{2}{*}{1200} & \multirow[t]{2}{*}{30} & \multirow[t]{2}{*}{30} & \multirow[t]{2}{*}{30} & \multirow[t]{2}{*}{31} & 30 & 30 & 30 & 30 \\
\hline & & & & & 35 & 38 & 40 & 41 \\
\hline \multirow[t]{2}{*}{1500} & 23 & 23 & 23 & 23 & 23 & 23 & 23 & 23 \\
\hline & 26 & 28 & 30 & 32 & 26,35 & 27,37 & 28,39 & 29,41 \\
\hline \multirow[t]{2}{*}{2455} & 23 & 23 & 23 & 23 & 23 & 23 & 23 & 23 \\
\hline & 26 & 28 & 30 & 32 & 26,35 & 27,37 & 28,39 & 29,41 \\
\hline
\end{tabular}

\section{Conclusion}

In this paper, first we derived a simple criterion by which a state of obsolescence can be constantly grasped, and showed there were some circumstances that the present decision can be made by the criterion without making the subsequent future decisions. We also clarified that some informa-tions on next replacement time could be obtained by parametric analysis of the criterion. Second, we gave the upper bound number of replacement under the above circumstance. The decision maker will be able to estimate the frequency of replacement for the planning period. Third we applied the proposed method to the prescribed case. The result of sensitivity analysis showed that it was relatively insensitive to changes of parameters.

Decision maker will be able to obtain informations and thus a guideline to equipment plan by the method.

Though this paper treated the case where there is a single replacement alternative at any time, it should be extended to the case where there are 
plural replacement alternatives at any time under various economic and technological circumstances.

\section{Acknowledgements}

I wish to thank Professor Hajime Makabe, Tokyo Institute of Technology, for his helpful suggestion and guidance throughout this paper, and Professor Toshiro Haga, Science University of Tokyo, for his insightful comments to complete this paper. I am also grateful to the reirees for their valuable comments.

\section{References}

[1] Bellman, R.: Equipment Replacement Policy. Journal of the Society for Industrial and Applied Mathematics, Vo1.3, No.3 (1955), 133-136.

[2] Dreyfus, S. E.: A Generalized Replacement Study. Journal of the Society for Industrial and Applied Mathematics, Vol.8, No.3 (1960), 425-435.

[3] E1ton, E. J. and Gruber, M. J.: On the Optimality of an Equal Life Policy for Equipment subject to Technological Improvement. Operational Research Quarterly, Vol.27, No.1 (1976), 93-99.

[4] Lin, B., Lee, J. and Senju, S.: A Study of Equipment Replacement Problem under Technical Progress -Analysis Is Based on Cost Side-. Journal of Japan Industrial Management Association (in Japanese), Vo1.35, No.2 (1984), 111-116.

[5] Lin, B., Lee, J. and Senju, S.: A Study of Equipment Replacement Problem under Technical Progress -On the Properties of Optimal Solutions-. Journal of Japan Industrial Management Association (in Japanese), Vol..35, No.6 (1985), 393-397.

[6] Nakamura, Z.: A Study of Equipment Replacement Problem -the Case where Equipment Purchase Price and Net Profit Change according to its Replacement Time and Use Interval-. Management Science of Journal of the Operations Research Society of Japan (in Japanese), vol.10, No.3 (1967), 148-159.

[7] Preinreich, G. A. D.: Economic Life of Industrial Equipment. Econometrica, Vo1.8, January (1940), 12-44.

[8] Senju, S. and Fushimi, T.: Engineering Economy (in Japanese). Japan Management Association, Tokyo, 1964.

[9] Stapleton, R. C., Hemmings, D. B. and Scholefield, H. H.: Technological 
Change and the Optimal Life of Assets. Operational Research Quarterly, Vo1.23, No.1 (1972), 45-59.

[10] Terborgh, G.: Dynamic Equipment Policy. McGraw-Hil1, New York, 1949.

Yasuo KUSAKA: Department of Business Management, Tokyo Metropolitan

College of Commerce, Harumi, Chuo-ku, Tokyo, 104, Japan 


\section{技術進歩の下での設備更新}

\section{東京都立商科短期大学 日 下 泰 夫}

技術進歩によって原価低減や性能向上の期待される新設備が計画期間にわたって出現するてとが予 想される時, 現有設備の経済的更新を簡単な指標を通じて判定する問題を検討する。

具体的には, 次の問題を考える。ある光学機械のアルミ・ダイカスト部品の平面削り, 穴あけ, ネ ジ切りを行うのに, 従来, フライス盤, ボール盤, タップ盤が使用されていた。乙の加工方法では,

1. 精度がでにくい， 2. 治具費が高い， 3. 運搬, 測定, 段取り等の工数がかかる，4. スペース が必要等の欠点が指摘されていた。そてで, てれらを改善するてとを目的として，ての工程を 6 ケ月 後に横型マシニングセンターに切り替える問題を検討している。

上記の様な原価低減を目的とした設備更新では以下の点が重要になる。

技術進歩の下で設備は絶えず陳腐化の危険にさらされているので, 意思決定者は設備の陳腐化の状 態を絶えず把握して，乙の情報を現在および将来の決定に適宜反映させていくことが必要となる。 特に, 意思決定者にとって, 設備を現在更新するかどうかは, 緊急かつ最も関心の樑い問題となる場 合が多い。しかも，乙の決定は将来とられる一連の決定に依存するという性格をもっている。

本研究では, 陳腐化の状態を把握する一つの簡単な評価基準を導出し, 意思決定者か計画期間中の すべての更新時点の系列を決定しなくても，てれによって現在更新するかどうかの決定を容易に下す ことの出来る状況を明らかにしている。

次に，乙の評価基準のパラメトリック解析を通じて，設備が少なくともいつまで保持されるべきか， あるいは, 少なくとあいつまでに更新されるべきか等のような, 次回の更新に関する情報の得られる ことを示している。さらに, 計画期間中の更新の密度を表わす指標として更新回数の上限を求めてい る。これらの情報は意思決定者の更新計画の指針となるであろう。

最後に, 前述の問題に対する適用例を示し, 種々の感度分析を通じて本方法の特性を調べている。 その結果, 現在の決定はパラメーターの変化に対して比較的安定していることが示される。 